\title{
Design strategies for exploring and bridging: Intersections of everyday life and decision- making for sustainability
}

\author{
HESSELGREN Mia ; HASSELQVIST Hanna and SOPJANI Liridona \\ KTH Royal Institute of Technology \\ * Corresponding author e-mail: miahes@kth.se \\ doi: 101
}

Transitions of unsustainable everyday practices into more sustainable ones require new approaches to explore possible futures and encourage change. Trying new practices and experiencing alternative configurations of sociomaterial assemblages can increase reflexivity as well as assist in exploring potential futures. Design can assist in co-creating possible futures and bridging discussions about the preferred strategies to reach them. If sustainability is defined as an on-going process calling for dialogue, there could be potentials for using practice-based design research, and in particular co-design approaches, at the intersections of these dialogues. By analysing methods for reflexivity and collaboration in two design research projects within sustainable mobility, we here suggest design strategies for prototyping change at an individual level and communicating the experiences of such change to people with power to trigger and direct change. This may be particularly useful for addressing sustainability which both requires dealing with complex problems and extensive collaboration.

keywords: sustainable mobility, co-design, bridging, living prototypes

\section{Introduction}

Many current transportation practices, especially fossil fuelled car driving, are unsustainable and cause severe problems for the planet and many of its inhabitants. Therefore, encouraging changes towards sustainable mobility solutions is of uttermost importance. In order for these changes to take place, people need to make different 
choices in their everyday lives to form more sustainable transportation practices. For the individual, this requires openness to change and willingness to try something new which, given the uncertainties and inconveniences that can come with changing practices, need to be accompanied by other support. To give up efficiency, flexibility and comfort associated with car driving, is for many considered unrealistic in the everyday puzzle of logistic activities. To replace car driving with sustainable transportation can be experienced as a transitional loss (Randall, 2009) that at first can be difficult and even undesirable. But for those who embrace that losing something can consequently mean gaining something else, and who discover new benefits when replacing one transport mode with another, the transition to sustainable practices can be smoother. To mourn a loss can also be considered a reconfiguration process (Sennett, 2012) where new meanings take shape when sacrifices are done. Trying new practices and experiencing different configurations of socio-material assemblages can increase reflexivity as well as assist in exploring potential futures therefore opening up new design spaces (Suchman, 2012).

However, for new everyday practices to emerge it is not enough with individuals being curious to try different practices out, but support by decision makers at various levels is also necessary (Strömberg et al., 2016). Establishing new social practices, defined as the interdependent relations between the three categories of elements: materials, competences and meanings, requires various types of support (Shove, Pantzar, \& Watson, 2012). To generate support for development of new sustainable transportation practices, collaborations between different actors are crucial (Kemp \& Loorbach, 2007; Verganti, 2008). It is difficult for a single stakeholder to successfully supply the materials (such as innovative vehicles and necessary infrastructure) as well as build the competences (like teaching how to drive it) and form new meanings (for example enabling acceptance of new norms) (Hesselgren \& Hasselqvist, 2016). When striving to design for changes towards sustainable mobility, with all its complex and wicked problems, we believe, cooperation between different stakeholders can be a fruitful way forward. Strengthened cooperation includes both formal and informal aspects of collaborating (Sennett, 2012). By bringing not only co-design tools and techniques but also co-design as a mindset and approach to design research (Sanders \& Stappers, 2012), we believe both these aspects can be cared for. Co-design as a mindset is based on an understanding that all people are creative. We argue that bringing everyday life to decision makers can be nourishing for cocreating potential sustainable futures.

Shaping futures clearly needs to be a democratic process but this is problematic when it comes to future sustainability transitions (Geels, 2010). Geels clarifies that sustainability transitions have three added complexities compared with many other societal transitions. First, sustainability is a normative goal whereby debates about relative importance will flourish and, since sustainability is a problem of collective good, many private actors will have no direct incentives to address sustainability issues. Second, there are different strategic approaches to making decisions for sustainability that depend on two opposing views: on one side there are those who advocate technical challenges to be met with green innovations, including top-down approaches and with emphasis on governments' responsibilities and experts' knowledge. On the other side, there are those who suggest a broad social transformation process including new lifestyles where bottom-up participatory approaches should be used to create engagement. Third, Geels claims, many 
of the sustainability challenges, including environmental problems such as climate change, are global, intangible and mainly about the future. These problems are more challenging as opposed to those that can be experienced locally, visibly and immediately. According to Geels, addressing these three added complexities when dealing with sustainability transitions requires crossovers between research fields. Also Robinson (2004) calls for transdisciplinary thinking where different fields, sectors and actors cooperate and form partnerships to address the challenges of sustainability. Robinson further argues that there is not one single successful approach available, but instead new forms of social learning are needed. Hence, sustainability can be seen as a process, rather than an endstate, encouraging multiple views to be expressed and experimental practices used to try out possible futures (ibid.). If sustainability is defined as an on-going process calling for dialogue and openness, there could be potential for using practice-based design research, and in particular co-design approaches, at the intersections of these dialogues.

We argue for bringing practice-based design research, as an approach with its methodologies, methods and tools, to other research fields with the aim to create change for sustainability. Our contribution is a set of design strategies for exploring prototypes of alternative future everyday lives, and for bridging everyday life with decision-making. We suggest a combination of strict and soft strategies and argue for balancing these strategies. In this paper we start by introducing practice-based research and relevant research methods within this approach, including interventions in everyday life and codesign methods. Following this, we describe how we have used these methods in two different design cases within sustainable mobility. Hence, this paper is both about method and its resulting learning. Concluding are discussions of the design strategies that facilitated exploring by doing and supported bridging by co-creating.

\section{Framing methods}

Design research, with a practice-based research approach, is when research activities are carried out through the design practice. Practice-based research in general can be useful to enrich the affected practice (Borgdorff, 2010). With practice-based research it is also possible to learn about the tacit knowledge within the practice and to make this embodied knowledge explicit and visible. Tacit knowledge encompasses the things we know, for example about a practice, but that is difficult to express verbally (Sanders, 2002). As Schön (1983) describes, learning by doing is one way to articulate knowledge and to be able to articulate the practice, you need to engage with it and to reflect in, and on, the action. Through this engagement in reflection, also the tacit knowledge can be teased out. This approach is foundational to practice-based research and is widely used by design, architecture and artistic research scholars.

These are also expanded in action research approaches, including participatory action research where both the participants and researchers engage in problem solving activities with intent to take action, which can be useful to understand change (Eden \& Huxman, 1996). Not only do these methods encourage openness but they also foster a research culture of inclusiveness and collaboration. In interventions created and studied in action research, the researcher often wants to both understand the situations as well as improve them (Cassell \& Johnson, 2006), which has similarities to design's intentions of creating better futures. Participatory design approaches traditionally emphasize empowerment and provision of resources for participants to actively deal with their problems (Bødker et al., 2000) and there is trust in the users themselves having expert knowledge on their own practices. As such, the designer's role is primarily to be the facilitator, as opposed to the 
expert on the individual practice, and to enable the participants' emerged knowledge to be used at a higher level. Designing together with users as a co-creative approach is particularly useful in generative design research (Sanders \& Stappers, 2012). Not only is it foundational within this approach to actively engage with users, similar to action research and participatory design research, but there is also an agreement to acknowledge all people as creative (ibid.). To release creativity, in for example generative sessions where future possibilities are co-created, different types of decision-making need to be encouraged (ibid.). To complement rational decision-making, where "thinking first" is followed by decision, it can be useful to introduce "seeing first" and "doing first" approaches (Mintzberg \& Westley, 2001). "Seeing first" is more related to the arts where many elements have to be combined into creative solutions. "Doing first" is typically used in crafts and design and it is particularly useful when the situation is novel and confusing, for example when disruptive technology is entering a field creating a situation of flux, or when addressing complex issues such as sustainability. When following this third approach, making and trying out are important activities and the focus is on experiences (ibid.).

We argue practice-based design research can enrich other research areas by bringing different ways of investigation. There are, for example in social science, calls for new ways of knowing and methods to research the increasingly complex and messy world. As Law (2004) claims, if researchers are to understand realities that are complex and messy, new ways to think and new practice are needed. Building on Law's call for new methods, Lury and Wakeford (2012) present inventive methods as ways to explore knowledge generation. Inventiveness is a matter of use and its capacity cannot be secured in advance, but reflexivity is one of the principal requirements (ibid.). Furthermore, Lury and Wakeford describe devices as hinges or clutches between concepts and practices, and as such they are terms for thinking processes. Other suggestions for new methods come for example from Suchman (2012) who proposes configuration as a method toolkit. This includes considering how humans and machines are configured and to possibly reconfigure these into new socio-material constellations. All these inventive methods are highly relevant in practice-based design research where devices and re-configurations of socio-material assemblages can be used as research methods, specifically when approaching research questions with an open mind in search for various alternatives rather than specific solutions. New or changed configurations of social-material constellations to purposely disrupt everyday practices can be a way to open up for new design spaces. Conducting research in the wild, where also non-researchers are invited into the research process may enable studying material-social interactions (Callon \& Rabeharisoa, 2003).

If sustainability is regarded as a process of adaption and continuous learning, the mindset of design including its methodology, methods and tools, can be important and useful. With a design approach encouraging "doing first", learning takes place all along. Also, learning by doing pays attention to many different layers of knowledge, including tacit knowledge, and through reflection in action, and on action, a culture of openness and ambiguity is fostered, particularly useful when trying to understand complexity and mess. 
With design's experimental practices and thinking across temporal scales possible preferred futures can be tried out. Furthermore, with a co-design approach, various actors, users as well as decision makers from different fields and sectors, can be brought together by the design process to collaborate. This inclusive and transdisciplinary process, where the designer acts as the facilitator and brings out the expertise within each and everyone, is useful to address sustainability challenges. The designer facilitates dialogue, which is needed when negotiating sustainability, by encouraging stories to be told and bringing these stories into the conversation. Possibly, design's primary role when engaging in sustainability is to make people realize that multiple options exist and that there is not one pre-decided future. Instead, there are many possibilities of how to live, and these need to be discussed and debated. Design can assist in co-creating possible futures and bridging discussions about the preferred ways of reaching them. Design methods can contribute to this in various ways, and in the two cases presented in this paper we highlight the methods used for each case and how the combinations of methods affected the prototypes of future mobility.

\section{Case 1 - A Car-free Year for three families}

In the research project "A Car-free Year" we explored transitions towards sustainable transportation practices by removing the car from the everyday life of three families with children living in Stockholm in Sweden. The families' cars were replaced by light electric vehicles, such as electric bikes, box bikes, a scooter and a four-wheeled motorcycle (see Figure 1) which the families selected and rented from the project. They also walked, biked, used public transport and used home delivery services.

The car-free year took place between October 2014 and October 2015. During the year the families formed new practices related to transportation and they were supported by the project for example by access to bike service and expert advice on challenges such as winter biking. Together with the project the families prototyped a life without cars, and by the end of the year they expressed that being car-free had become normal.

To explore a broad set of challenges related to not owning a car, we selected families that were different in terms of previous car use, type of housing, age of children, and activities they engaged in. Although the families previously used the cars to different extents, replacing car trips with alternative transportation modes had a great impact on all the families' lives. It affected how they dealt with situations such as going to work, taking children to sports activities, doing grocery shopping, going on holidays, meeting family and friends, and renovating at home.

We studied the changes in transportation related practices mainly through monthly interviews and observations in the families' homes. To encourage reflection, and to elicit tacit knowledge, the parents in the families used a trip diary where they, one week per month, registered facts about their trips as well as emotional aspects and other thoughts on their new practices (see Figure 2). To further support reflection, the parents used the mobile app Moves ${ }^{1}$ to automatically log all their trips and the connected tool Move-oscope $^{2}$ to visualise their travel patterns (see Figure 2 ). Since the families were used to having access to a car, many reflections on being car-free were made in relation to their

\footnotetext{
${ }^{1}$ https://moves-app.com/

${ }^{2}$ http://move-o-scope.halftone.co/
} 
previous car use. How other people approached transportation and what others said about their participation in the study were also triggers for reflection.

While the families did not have access to their own car during the year, they had the option of borrowing or renting a car (or taxi) 24 times, when they could find no other solution. They documented all such trips on a designated sheet (see Figure 2), which gave

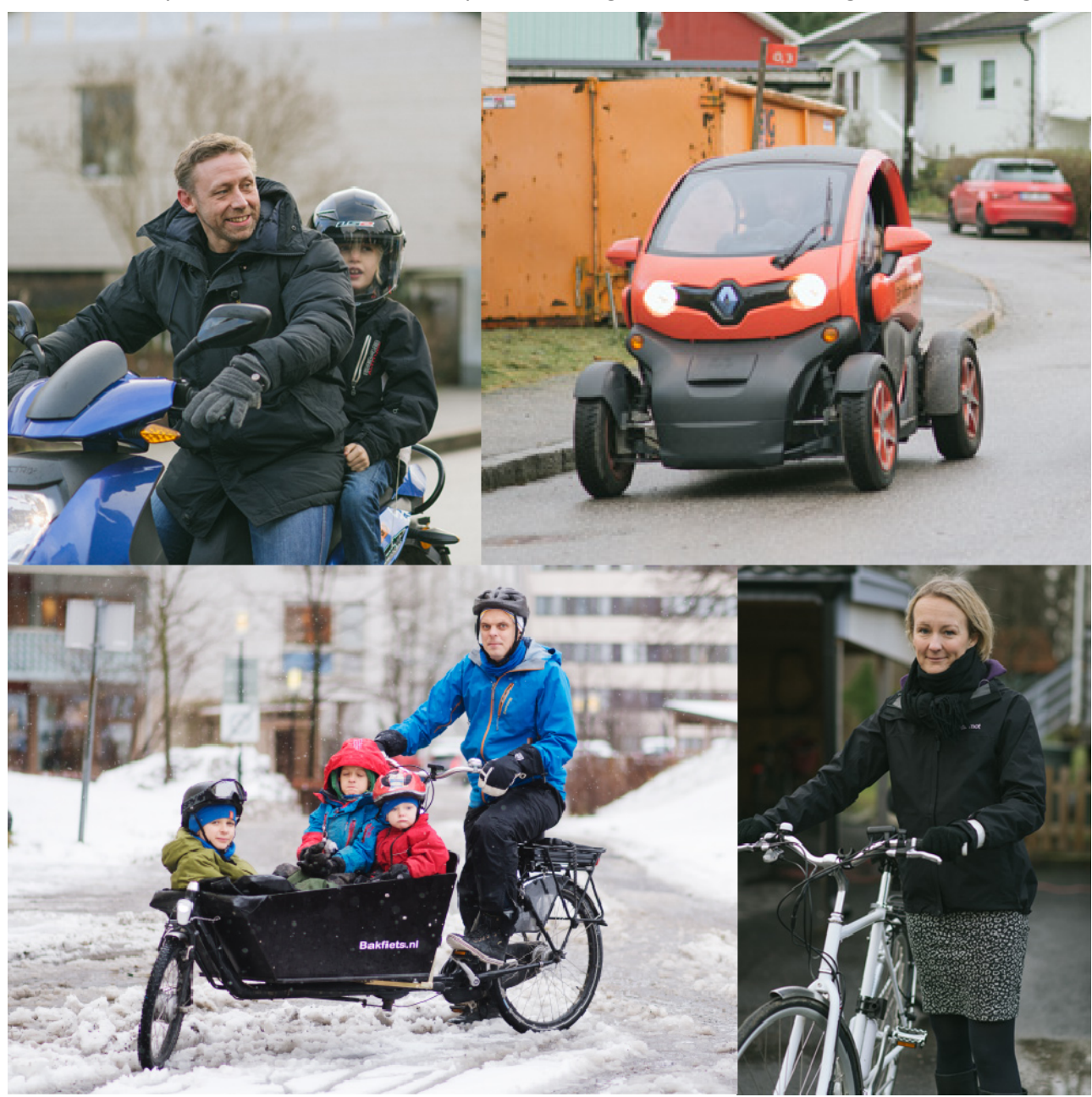

Figure 1 Examples of the light electric vehicles. Going clockwise from top left, is the scooter, the four-wheeled motorcycle, the bike and bottom left is one of the box bikes.

us insights into the perceived limitations of car-free living. The option of using a car was for example used for buying a new toilet when an old one broke down, going to a summer house in an area with poor public transport, and coming home from a party on New Year's Eve. The allowed car trips became a safety net, although the participants were very motivated to minimise the number of car trips they made.

Based on the families' stories about positive and negative experiences of car-free life and practical and emotional aspects of changing to more sustainable transportation practices, 
we created design concepts for how products, services and the city better could support car-free living. We could not cover all aspects of car-free living in the concepts but we strived for a variety in types of practices represented, main users and stakeholders involved, and types of support imagined. The concepts were developed together with a design company and the families were also involved in the process. Collaboration between different stakeholders was central to many of the concepts, which included ideas such as workplaces as enablers of trying alternative transportation modes, the city rewarding cyclists with points to be used to pay for bike services, shared digital public transport cards for children's sports teams, and links between physical infrastructure and digital tools that highlight benefits of alternatives to the car. The concepts were visualised as non-

photorealistic $2 \mathrm{D}$ images that aimed at striking a balance between being concrete enough to convey the families' experiences and abstract enough to trigger new ideas (see Figure 3 for an example). As a complement to the concepts, we created a video where the families shared stories from the car-free year and reflected back on the experience.

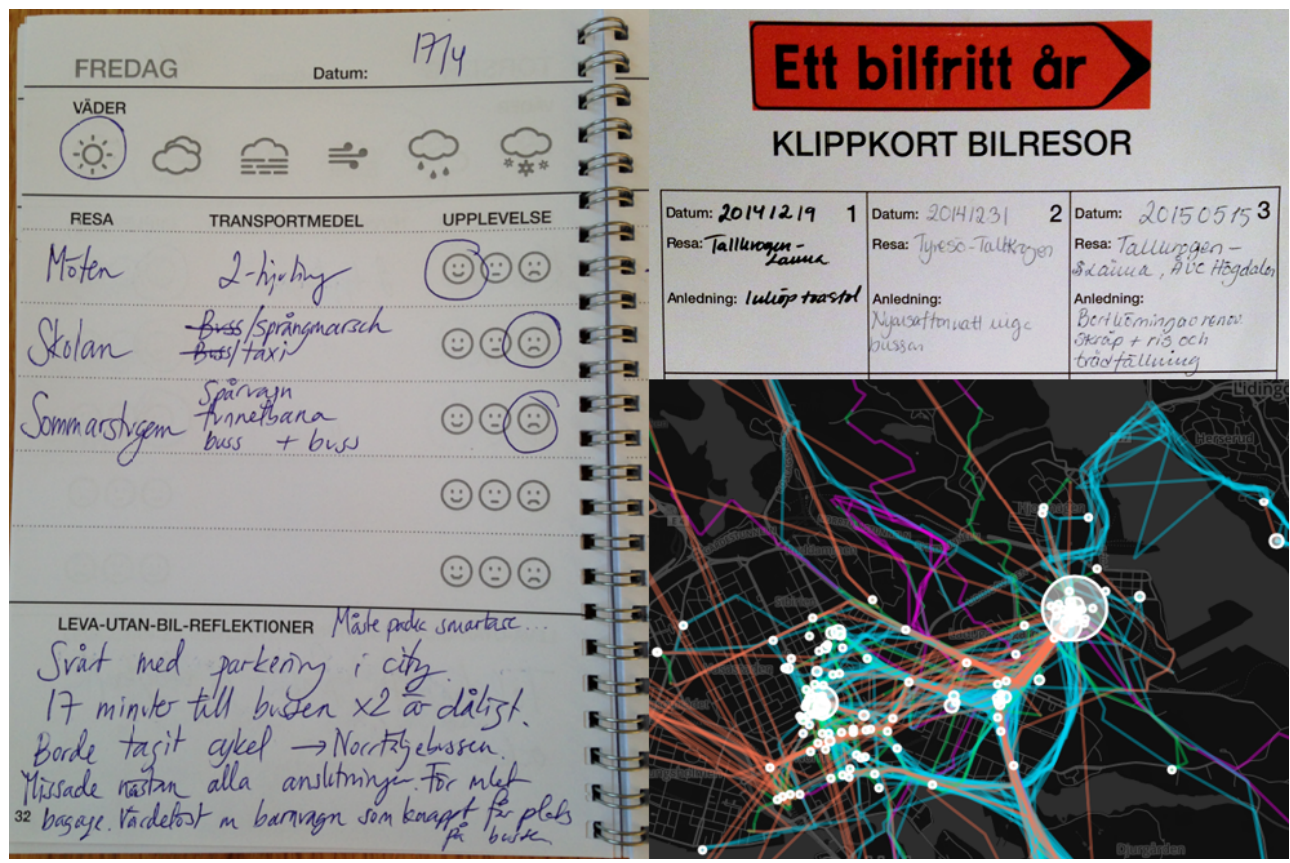

Figure 2 Examples of trigger material: trip diary (to the left), 24-car-trips card (at the top right) and visualisation of trips for different transportation modes (at the bottom right).

The concepts, in combination with the video, were used to communicate the knowledge from the study in several meetings with decision makers with an influence on transportation practices, such as local and national politicians, and companies. The aim was to support reflection on possible futures for sustainable mobility in relation to the responsibilities and power of the respective stakeholder. Due to the decision makers' pressed schedules, the meetings did only leave room for beginning to discuss alternative futures. The discussions shifted between thoughts on details, such as choice of colours on road signs, and greater implementation challenges and additional opportunities. One of the main barriers identified for most of the concepts was that implementation depended not only on the stakeholders in the room but was also related to responsibilities of other decision makers. In general, the concepts and the video were appreciated for giving a rich 
picture of transportation related everyday practices and challenges and opportunities of car-free living.

For more details on the outcomes of the project and implications for design of services and technologies supporting sustainable transportation, see our previous work (Hesselgren \& Hasselqvist, 2016).

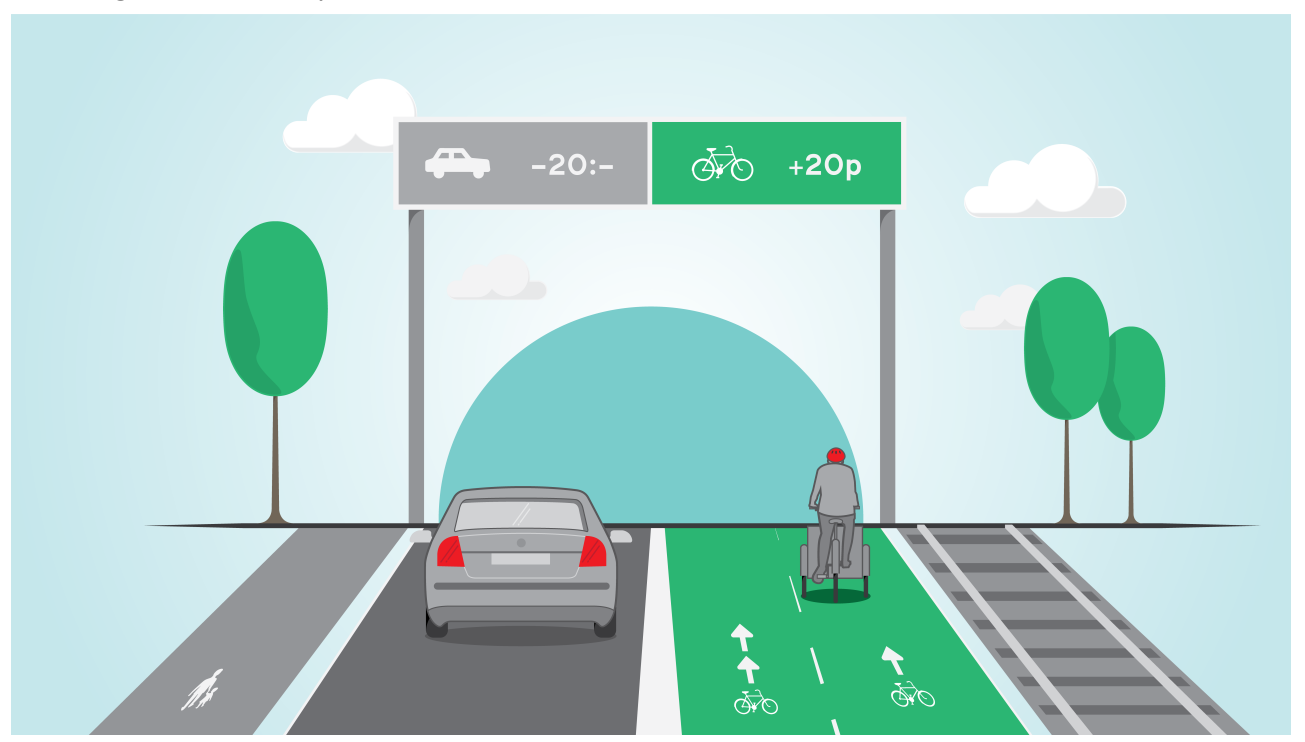

Figure 3 Concept example describing possible future biking infrastructure where cyclists are rewarded points that can be used to pay for bike services.

\section{Case 2 - Mobility Pool and no car to work at two workplaces}

In the study Mobility Pool, a collaborative project between academia, private sector and public actors, we explored how two large workplaces could support their employees in commuting to, in between and from work with an alternative to fossil-fuelled cars. A pool of ten light electric vehicles, which was a four-wheeled motorcycle (see Figure 4), was set up as a mobility service to engage two types of users: people taking their fossil-fuelled car every day to work (in the project referred to as caretakers) and people commuting with public transport, bikes, or walking to work but in need of a vehicle during office hours for meetings between offices or errands outside of the office (in the project referred to as daytime users). In the project we aimed to intervene in the routines of going to work or travelling for short distances by providing more environmentally friendly alternatives.

Between September 2015 and September 2016, 16 users joined as caretakers of the light electric vehicles and used them every day to commute to and from work instead of using their private, fossil fuel-driven, cars. To some extent, the new vehicles also replaced their private cars in the evenings and during weekends. The light electric vehicles were provided by the project and the users volunteered as caretakers and paid a monthly fee to co-own the vehicles during the project. This co-ownership included rules such as bringing the vehicles everyday to and from work and responsibilities such as daily maintenance and charging of the vehicles. In addition, they shared the vehicles with other colleagues (the 


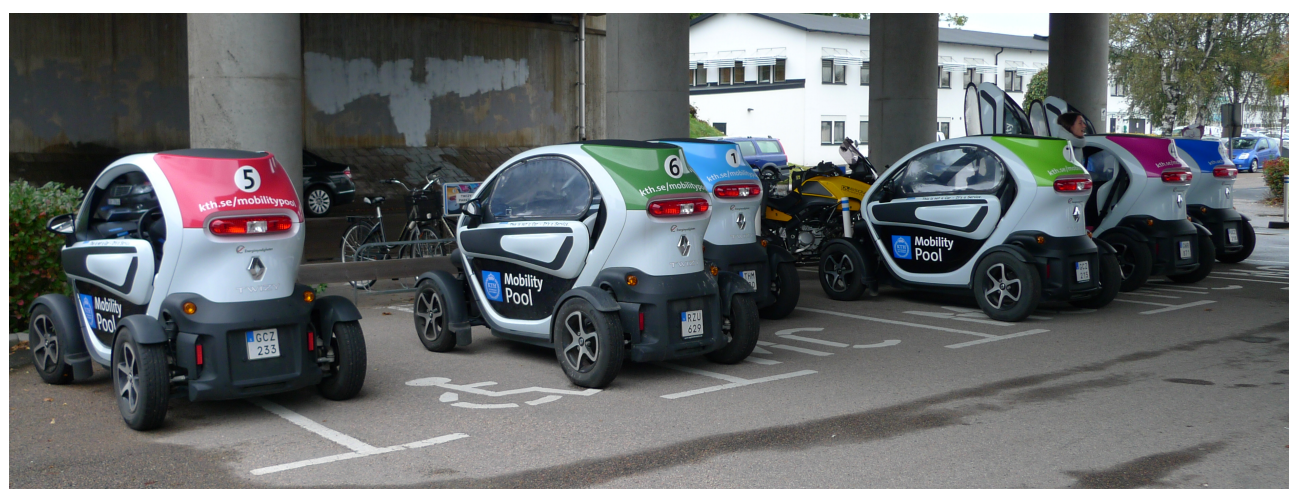

Figure 4 Some of the light electric vehicles at one of the workplaces.

daytime users) during work hours. The caretakers had different personalities, lifestyles, household sizes, and living distances from their workplace, which allowed us to explore and understand diverse everyday practices and how the combination of a light electric vehicle with bike or public transport could support those practices. Before the project, all caretakers primarily went by car to work but they were interested in trying new possibilities. For one of the participating workplaces the project was divided in two periods of six months, where seven caretakers were recruited for the first six months, and then seven new caretakers were recruited for the next six months. In the other workplace, with a smaller pool of light electric vehicles, two users signed up to be caretakers. At both workplaces, the light electric vehicles were available during daytime for all employees in the departments where the pool was set up. The daytime users could book the vehicles for use during work hours through a digital booking system, and this type of use was free of charge.

The caretakers were of our primary focus since we wanted to explore how the light electric vehicles affected both their commuting practices and their practices outside of work. Thus, this group of users was heavily engaged in the process of exploring future scenarios together with the researchers. We conducted sets of deep interviews with caretakers before, during, and after trial periods, as well as organized workshops during the trial to capture their experiences, both at individual and group level. Different design methods were used to engage them in discussions such as mapping experience journeys, storytelling, mapping values, mapping barriers and enablers as well as visualizing activities (see Figure 5). The caretakers were important actors in the development process of the new mobility service, and they reflected on their daily practices including the challenges and benefits of giving up their private cars. Their involvement allowed them to both reflect on their practices and provide input for us researchers to study how transformation of transportation practices could be facilitated.

During the workshops, the caretakers shared their stories and experiences with the group and were involved in a dialogue about minimizing the use of their private car. They talked about their everyday lives in which at times the new mobility alternative was a huge support, such as for quick grocery shopping. At other times it had brought them challenges, like when fitting bulky sports equipment or doing large shopping with the family. These were constraints that emerged as they lived with the new vehicles, and through experiencing it, they were able to reflect and make more conscious decisions about their choices of transport. As these trials were part of developing the innovation 


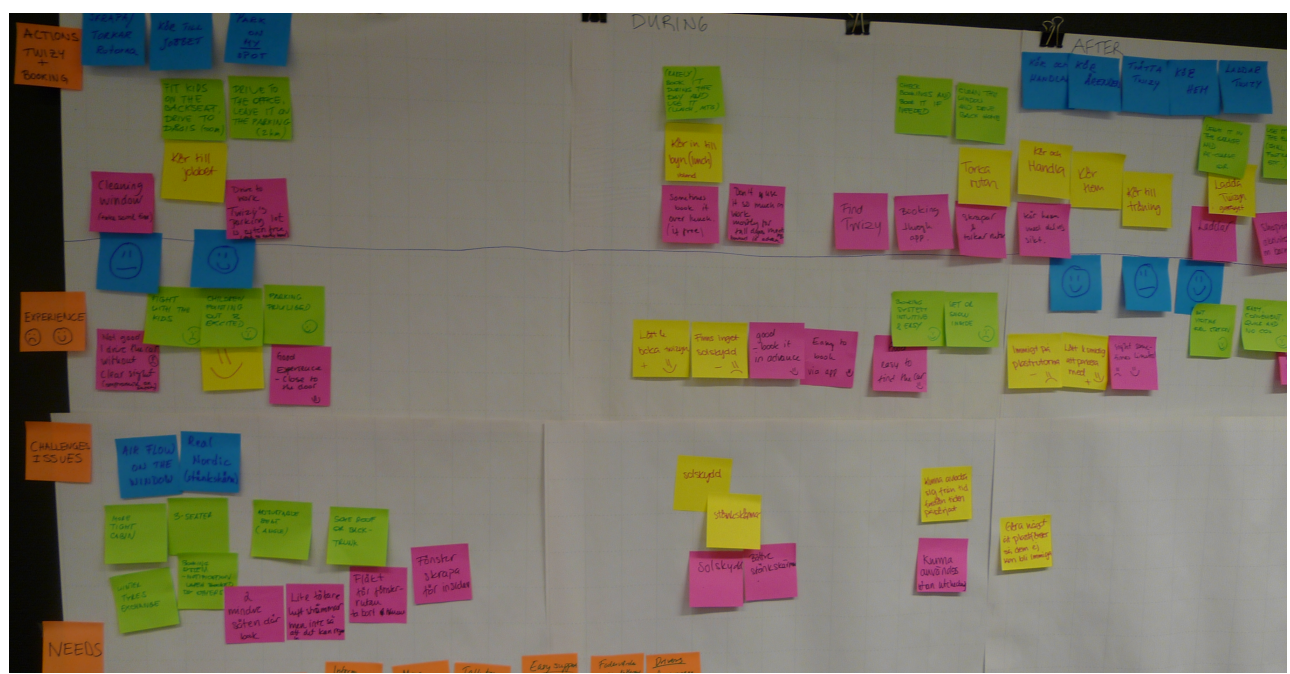

Figure 5 Example of experience journey co-created together with caretakers.

with users in focus, these experiences were input for the design and development phase. This input, brought through analysis of interviews and workshop materials was brought to the other stakeholders in the project whom were decision makers in the process of developing solutions towards more sustainable transport futures. The caretakers' experiences provided room for dialogue and alternative design spaces. With tangible materials, such as rough films of users presenting their experiences and maps of post-it notes, the decision-making could be further informed and, in generative sessions, storyboards and scenarios were co-created (see Figure 6). For more information regarding the project, see our previous work (Sopjani et al., 2016).

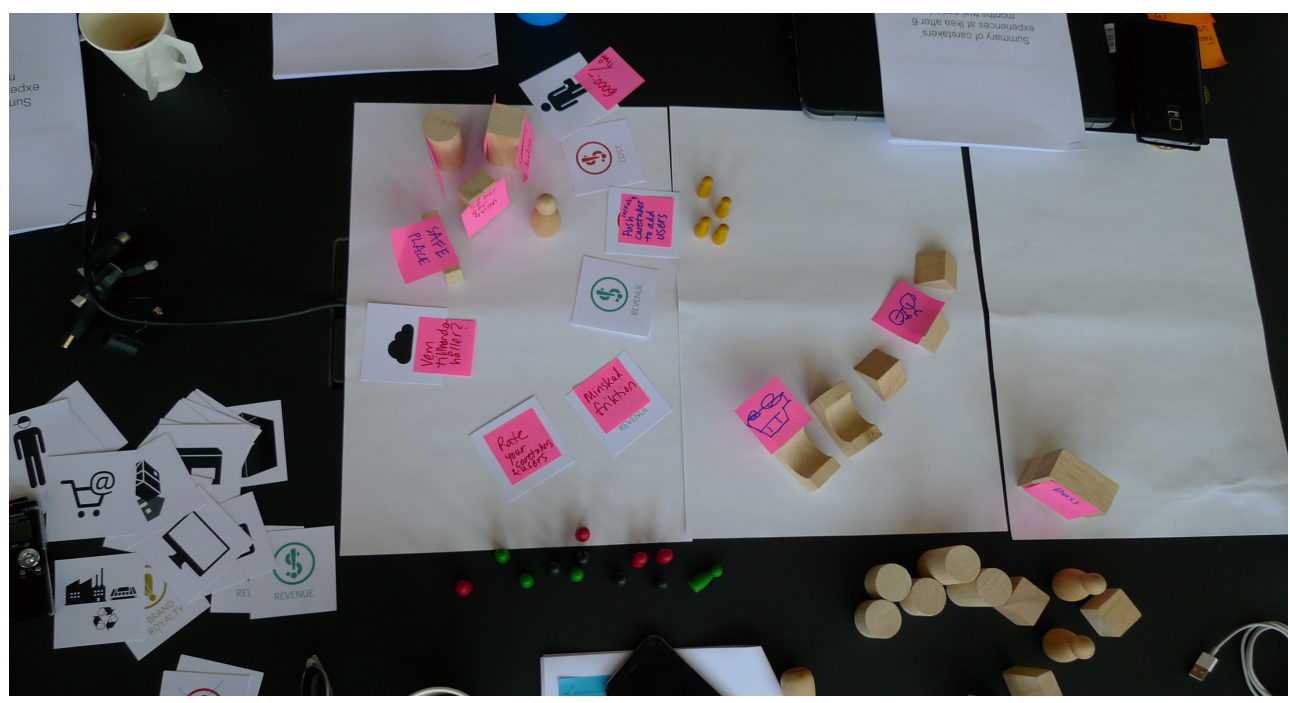

Figure 6 Example of concept generation and business modelling co-created with stakeholders. 


\section{Discussing exploring and bridging}

While the cases above have many similarities, there are also important differences in how practices were explored and how participants' stories were bridged to decision makers. Following we discuss how some of the strategic choices were balanced in the two cases and how this facilitated reflection and co-creation. These design strategies, we hope, can be inspiration for others who aim at creating change for sustainability.

Each of the projects had two separate phases. In the first phase participants tried, and learned from, new everyday practices and we aimed to facilitate this by using different strategies for exploring. The second phase was related to bringing the participants' learning forward in design conceptualisation and communication of everyday life to decision makers. In this phase we tried different strategies for bridging (Sanders \& Stappers, 2012). The strategic choices were balanced to achieve co-creation and hence learn for sustainability. We explored prototypes of alternative everyday lives and bridged this learning to decision makers. We believe this is particularly useful when it comes to addressing sustainability, which both requires addressing complex problems and extensive collaboration (Schot \& Geels, 2008). Design is motivated by both problem solving, connected to the physical world, and sense making, more related to the social world (Manzini, 2015). As such, there are potentials in using design to address sustainability. In our framing, design approaches initiated dialogues that were not limited to either topdown or bottom-up perspectives, but created intersections across. However, a limitation in this paper is that the framing occurred in a Scandinavian context where the tradition of participatory problem solving may influence openness and inclusiveness in decisionmaking. Trying out these strategies in other cultures and traditions of decision-making may lead to different actions.

\section{Exploring prototypes of alternative everyday life}

A significant difference between the two cases described is the strategies for exploring alternative everyday life and learning while doing. These can be seen as moving on a scale from strict to soft ways of trying and learning in the exploration phase. When prototyping everyday life, making people try out alternatives, the purpose is to reconfigure their lives and practices. Configuration has simultaneously a reflexive and generative character (Suchman, 2012) that we wanted to explore and different strategies were used to do so.

Table 1 Summary of strict and soft strategies in exploring.

\begin{tabular}{|l|l|l|l|}
\hline EXPLORING & Strict strategies & Soft strategies \\
\hline Trying & What & Removals & Add-ons \\
\hline & How & Rule (top-down) & Guide (bottom-up) \\
\hline Learning & What & Reports & Discussions \\
\hline & How & Formal & Informal \\
\hline
\end{tabular}

The strict strategies for trying out alternatives can create more radical change, which however can be more difficult to test in real life. Possibly, participants might bend the rules to fit the prototype to their everyday lives. Using soft strategies to prototypes of everyday life, can be easier for the participants to adapt to, but might only create incremental change. Also in the learning phases of the projects, the categories of strict and soft strategies can be applied as different ways to access knowledge about the participants' everyday lives in the prototypes. Strict strategies, including formal reports 
and meetings, can be used to access required detailed information, but they can also entail a focus on rational information which not necessarily enables a deeper understanding. With soft strategies, informality can instead be emphasized to possibly bring out more emotional reflections. Inviting discussions, as a soft strategy, can encourage reflections and development of mutual learning amongst both participants and researchers, but require mutual trust for more sensitive issues to be revealed. (See Table 1 for a summary of what and how the strict and soft strategies were used when trying and learning.)

In the Car-free Year project, we took a more radical approach by removing the car from the families' everyday lives, which also pushed them far towards forming sustainable transportation practices. However, the strict strategy of disrupting and reconfiguring the families' practices was softened by the 24-trip car-allowance, in order to make participation in the study seem less impossible. The softer overall strategy in the Mobility Pool project, where instead a new vehicle was added to the vehicles the participants already owned, had a smaller impact on the participants' lives. To encourage exploration of new practices, the intervention was made stricter by rules regarding for example when to bring the light electric vehicles to work.

During the car-free year, the participants could choose for themselves, which types of light electric vehicles they wanted to use. This softer strategy enabled them to try various practices, and they were also allowed to change their set-ups throughout the project period. In Mobility Pool, on the other hand, the stricter strategy was implemented by simply adding the particular light electric vehicle to encourage substitution of the private vehicle. However, the participants in this project softened this themselves by using the vehicle more differently and bending the rules. In both cases, finding a balance between hard and soft ways to try out alternative practices was important for making the most out of each case. We found that experimenting in the wild requires a balance of reconfigurations, to enable life to still go on.

To get to the knowledge the participants obtained throughout the project periods, the research teams used various methods and tools. In A Car-free Year, the travel diary was a helpful more formal tool to encourage reflections and for the participants to report their trips. The diary had a formal structure, but still allowed for open reflections. This was also useful to prepare the participants before the monthly interviews. The one-hour deep interviews had a formality in their semi-structured discussion guides. At the same time, the informality of these interviews, often taken place around the kitchen tables in the families' homes, softened the dialogue. Also the one-year research process encouraged the informality of these discussions as all project members got to know each other. In Mobility Pool, the settings for interactions with participants were more formal, as they took place at the workplaces together with colleagues. However, as these were conducted as creative workshops, informality was encouraged but the primary focus on work life, as opposed to private life, made these discussions more formal.

The learning in Mobility Pool was also facilitated in the co-creative sessions where the participants were asked to generate possible refinements of the product-service system. Here, the learning developed mutually with the discussions in these co-creative sessions aided by the provided tools. In A Car-free Year, the travel diaries and digital tools provided the research team with a vast amount of information, but the more emotional aspects, 
such as the challenges of living outside the car-norm, came from dialogues after trust had developed. Balancing formal with informal, and reports of details with reflective discussions, were necessary strategies to understand the participants' experiences.

\section{Bridging everyday life and decision-making}

In the next phase of the two research projects, different strategies were used to bridge everyday life and decision-making. These strategies can also be viewed as moving on a scale from strict to soft strategies for conceptualizing and communicating. When conceptualizing, knowledge from the prototypes of alternative everyday lives is packed into concepts of systems. Designing at a system level requires attention to the different parts as well as their relations (Ceschin \& Gaziulusoy, 2016). When communicating the findings with decision makers, the concepts invite to discussions and co-creations where the decision makers can use the families' and users' stories to create their own.

Table 2 Summary of strict and soft strategies in bridging.

\begin{tabular}{|l|l|l|l|}
\hline BRIDGING & Strict strategies & Soft strategies \\
\hline Conceptualising & What & Elaborate & Sketchy \\
\hline & How & Professional & Inclusive \\
\hline Communicating & What & Presentations & Participations \\
\hline & How & Formal & Informal \\
\hline
\end{tabular}

Use of strict strategies in conceptualisation can help to create trustworthy messages, but can also distance the audience. Soft strategies can be used to include the audience to ensure commitment, but even if a vision is shared it can be difficult to align for change. Different strategies can also be used when communicating concepts to decision makers. Strict strategies for communication can ensure expected information is brought to decision makers, but this does not guarantee change will take place. Communication with the use of soft strategies can inspire to think beyond existing solutions and open up for imagination of potential futures, however the direction of change can be more ambiguous. (See Table 2 for a summary of what and how the strict and soft strategies were used when conceptualising and communicating.)

In A Car-free Year, the concepts that were co-created with the design agency, describe socio-material relations of how a city could welcome more car-free families. The concepts were built on extensive analysis of and attention to system relations as strict strategies to conceptualisation. However, to clarify that these were proposals, not solutions, they were visualized as non-photorealistic $2 \mathrm{D}$ renderings. To further balance, and soften the concepts, the $2 \mathrm{D}$ visualisations were complemented with the video with the families' stories. The families own words brought concrete details from everyday life to the more high-level and abstract concepts.

In the Mobility Pool project, on the other hand, the level of the concepts brought into these co-creative sessions were intentionally very sketchy and not as finished and detailed as in the Car-free Year project. In this project, the conceptualization mainly took place in co-creation activities, emphasizing soft strategies, and included people who were not so used to creative work. However, as we, in line with e.g. Sanders \& Stappers (2012), believe that all people are creative, this simply implied that more attention needed to be paid to the prerequisites of the co-creative sessions. Also the other stakeholders in this project were brought into similar inclusive co-creative sessions further developing the concepts of 
possible future pool solutions. With service design methods such as customer journey mapping (Stickdorn et al., 2011), it was possible to move beyond the product level to include a system perspective to identify some of the real challenges around making the employees refrain from travelling by car to work. As the concepts were deliberately presented as unfinished, emphasized by the inclusive making of them as the sessions went along, and at the same time specifically related to the particularities and details of each workplace, the dialogues around the concepts were enabled.

The projects also used different strategies, soft and strict, for communication. In the Mobility Pool project, as the stakeholders with decision making powers participated as project members, the communication took place over the whole project period and cocreative sessions were immersion rich. This allowed for emphasis on soft strategies. In some of these longer sessions, the stakeholders were, through the concepts and films, immersed into the everyday lives of the participants who had tried new transportation practices. The discussions became more informal as the project members got to know each other over the project period. The initial concepts were co-created as part of the communication process and, by including all stakeholders in the dialogue, new values, also at corporate and societal level, of shared mobility solutions were identified. Even though all stakeholders shared the same vision to improve conditions towards more sustainable mobility, it was difficult to get alignment around the respective strategies for reaching the vision as each stakeholder also had to relate to its own organisation's strategies.

In A Car-free Year, the communication with decision makers was instead organised as a series of presentations with politicians and corporate decision makers. This meant an emphasis on more strict strategies. These presentations were shorter and more formal but the concept visualizations and films still managed to open up the discussions and the decision makers could start imagining possible future options. The stories of how people had lived in prototypes of possible futures enabled empathy for these people to develop as well as provided context for imagination, also among the politicians, creating possibilities for alternative design spaces. However, the decision makers quickly located others' responsibilities for enabling sustainable mobility changes. This points at the need for a co-creative mindset enabling dialogue for sustainability transitions.

\section{Moving on}

In this paper we present two design research projects where sustainable transportation practices were tried out in real life and the results from living in these prototypes of potential futures were brought to decision makers. We discuss how this practice-based design research, including the applied co-design methods, increased participants' reflexivity and encouraged stakeholders' collaboration. By paying attention to reflexivity and collaboration, we suggest design strategies for prototyping change at an individual level and communicating the experiences of such change to people with power to trigger and direct change. Practice-based design research with a co-creation mindset, we believe, can be a complement to transition research for sustainability. This particular research approach, we argue, can be useful in dealing with complex problems by openly exploring potential futures, and supporting communication processes by inclusively bridging everyday life to decision makers. These applied strategies may serve as inspirations for others to try out and learn from as well as potentially push for making change with a designerly co-creative mindset. 


\section{References}

Bødker, S., Ehn, P., Sjogren, D., \& Sundblad, Y. (2000). Co-operative Design-perspectives on 20 years with "the Scandinavian IT Design Model." In Proceedings of NordiCHI 2000, Stockholm, October 2000. (pp. 1-12).

Borgdorff, H. (2010). The Production of Knowledge in Artistic Research. In The Routledge Companion to Research in the Arts (pp. 44-63). Routledge.

Callon, M., \& Rabeharisoa, V. (2003). Research "in the wild" and the shaping of new social identities. Technology in Society, 25(2), 193-204. https://doi.org/10.1016/S0160-791X(03)00021-6

Cassell, C., \& Johnson, P. (2006). Action research: Explaining the diversity. Human Relations, 59(6), 783-814. https://doi.org/10.1177/0018726706067080

Ceschin, F., \& Gaziulusoy, I. (2016). Design for Sustainability: An Evolutionary Review. 2016 Design Research Society 50th Anniversary Conference, 1-24.

Eden, C., \& Huxman, C. (1996). Action research for management research. British Journal of Management.

Geels, F. W. (2010). Ontologies, socio-technical transitions (to sustainability), and the multi-level perspective. Research Policy, 39(4), 495-510. https://doi.org/10.1016/j.respol.2010.01.022

Hesselgren, M., \& Hasselqvist, H. (2016). Give car-free life a try: Designing seeds for changed practices. In Proceedings of DRS2016: Design + Research + Society-Future-Focused Thinking.

Kemp, R., Loorbach, D., \& Rotmans, J. (2007). Transition management as a model for managing processes of co-evolution towards sustainable development. International Journal of Sustainable Development \& World Ecology, 14(1), 78-91. https://doi.org/10.1080/13504500709469709

Law, J. (2004). After Method. After Method: Mess in Social Science Research. https://doi.org/10.4324/9780203481141

Lury, C., \& Wakeford, N. (Eds.). (2012). Inventive methods: The happening of the social. Routledge.

Manzini, E. (2015). Design, when everybody designs: An introduction to design for social innovation. MIT press.

Mintzberg, H., \& Westley, F. (2001). Decision Making : It' s Not What You Think. MIT Sloan Management Review, 42(3), 89-94. https://doi.org/10.1108/eb000998

Randall, R. (2009). Loss and Climate Change: The Cost of Parallel Narratives. Ecopsychology, 1(3), 118-129. https://doi.org/10.1089/eco.2009.0034

Robinson, J. (2004). Squaring the circle? Some thoughts on the idea of sustainable development. Ecological Economics, 48(4), 369-384. https://doi.org/10.1016/j.ecolecon.2003.10.017

Sanders, E. B. (2002). From User-Centered to Participatory Design Approaches Elizabeth B.-N. Sanders SonicRim. Design and the Social Sciences, 7.

Sanders, L., \& Stappers, P. J. (2012). Convivial design toolbox: generative research for the front end of design. Orbis Litterarum: International Review of Literary Studies (Vol. 61). Retrieved from http://www.gbv.de/dms/bowker/toc/9789063692841.pdf

Schot, J., \& Geels, F. W. (2008). Strategic niche management and sustainable innovation journeys: theory, findings, research agenda, and policy. Technology Analysis \& Strategic Management 20(5), 537-554. https://doi.org/10.1080/09537320802292651

Schön, D. (1983). The Reflective Practitioner. Pediatrics, 116(6), 1546-52. https://doi.org/10.1542/peds.2005-0209

Sennett, R. (2012). Together: The rituals, pleasures and politics of cooperation. Together: The Rituals, Pleasures and Politics of Cooperation, 15(4), 1-337. https://doi.org/10.1139/apnm-20130536

Shove, E., Pantzar, M., \& Watson, M. (2012). The Dynamics of Social Practice. The Dynamics of Social Practice. Everyday Life and How It Changes, 1-19. https://doi.org/10.4135/9781446250655.n1

Sopjani, L., Stier, J. J. \& Ritzén S. (2016), User involvement in disruptive innovation - A study on users of a light electric vehicle sharing system. Proceedings of the $23^{\text {rd }}$ Innovation and Product Development Management Conference, Glasgow, UK. 
Stickdorn, M., Schneider, J., Andrews, K., \& Lawrence, A. (2011). This is service design thinking: Basics, tools, cases. Hoboken, NJ: Wiley.

Strömberg, H., Rexfelt, O., Karlsson, I. C. M. A., \& Sochor, J. (2016). Trying on change - Trialability as a change moderator for sustainable travel behaviour. Travel Behaviour and Society, 4, 60-68. https://doi.org/10.1016/j.tbs.2016.01.002

Suchman, L. A. (2012). Chapter 4: Configuration. In Inventive Methods: The Happening of the Social. Verganti, R. (2008). Design, meanings, and radical innovation: A metamodel and a research agenda. Journal of Product Innovation Management, 25(5), 436-456. https://doi.org/10.1111/j.15405885.2008.00313.x

\section{About the Authors:}

Mia Hesselgren is a PhD student in Design and Sustainability. Her research focus is on how methods of service design, strategic design and collaborative design can be used in sustainable development and for sustainability transitions.

Hanna Hasselqvist is a PhD student in Interaction Design and Sustainability. Her research focuses on how interactive technologies can be designed to support sustainable practices and in which contexts they may be useful.

Liridona Sopjani is a graduate in Sustainable Design and Sustainable Development. Currently a PhD student in Integrated Product Development where her research is focusing on socio-technical transitions to sustainability through disruptive innovation and means of co-creation. 